\title{
Review Article \\ Service Operations Optimization: Recent Development in Supply Chain Management
}

\author{
Bin Shen \\ Glorious Sun School of Business and Management, Donghua University, Shanghai 200051, China \\ Correspondence should be addressed to Bin Shen; binshenjerry@gmail.com
}

Received 5 September 2014; Accepted 9 December 2014

Academic Editor: Bin Jiang

Copyright ( 2015 Bin Shen. This is an open access article distributed under the Creative Commons Attribution License, which permits unrestricted use, distribution, and reproduction in any medium, provided the original work is properly cited.

\begin{abstract}
Services are the key of success in operation management. Designing the effective strategies by optimization techniques is the fundamental and important condition for performance increase in service operations (SOs) management. In this paper, we mainly focus on investigating SOs optimization in the areas of supply chain management, which create the greatest business values. Specifically, we study the recent development of SOs optimization associated with supply chain by categorizing them into four different industries (i.e., e-commerce industry, consumer service industry, public sector, and fashion industry) and four various SOs features (i.e., advertising, channel coordination, pricing, and inventory). Moreover, we conduct the technical review on the stylish industries/topics and typical optimization models. The classical optimization approaches for SOs management in supply chain are presented. The managerial implications of SOs in supply chain are discussed.
\end{abstract}

\section{Introduction}

The importance of service operations (SOs) has been growing significantly in the latest decade. SOs management focuses on how excellent services could be delivered effectively. To realize the correlated business value and achieve business success, the concept of SOs has become quite popular throughout the whole business process. It is well known that supply chain is the important areas in SOs management, which are the key to deliver values to consumers and, as a result, improve customer satisfaction and create great business value [1].

Supply chain management is pervasive and is creating the considerably huge values to both firms and customers [2]. Many scholars claim that supply chain is the tool to guarantee the service quality $[3,4]$. However, with the prevailing trend of electronic commerce, SOs management is increasingly critical in supply chain. For example, the attractive online advertising films provide consumers' psychological boost in purchasing intention; online retailers (e.g., Amazon and Taobao) attract millions of customers because they are able to not only purchase food, fashion products, toys, books, electronics, film tickets, optimal services, and nursery items in a one-stop integrated place, but also receive the products in a prompt way supported by efficient delivery services [4].
Optimal control approach is popularly adopted in SOs management. The theory of optimal control is a mature mathematical approach with numerous applications in science, engineering, and business [5]. Optimal control has been applied to determine the optimal ways in controlling a dynamic system, such as the optimal decisions in SOs management system. In SOs literature, optimal control techniques are commonly adopted to manage the tradeoff strategies between service quality and operational cost. Providing good services could enhance the customers' satisfaction, and then customers are more willing to pay premium for the value-added experience. However, enhancing service quality incurs a large number of operational costs. Thus, in order to maximize profit, service providers have to manage the tradeoff between customer satisfaction and operational costs by the scientific optimization approaches.

In this study, we focus on investigating the recent development of SO optimization in supply chain management. Our objectives are to explore how firms sustain the excellent service and in the meanwhile gain business success. The main contributions of this paper are to (1) summarize the recent development of SOs in supply chain management by categorizing them into 4 different industries and 4 various features, (2) describe how SOs in supply chain are performed 


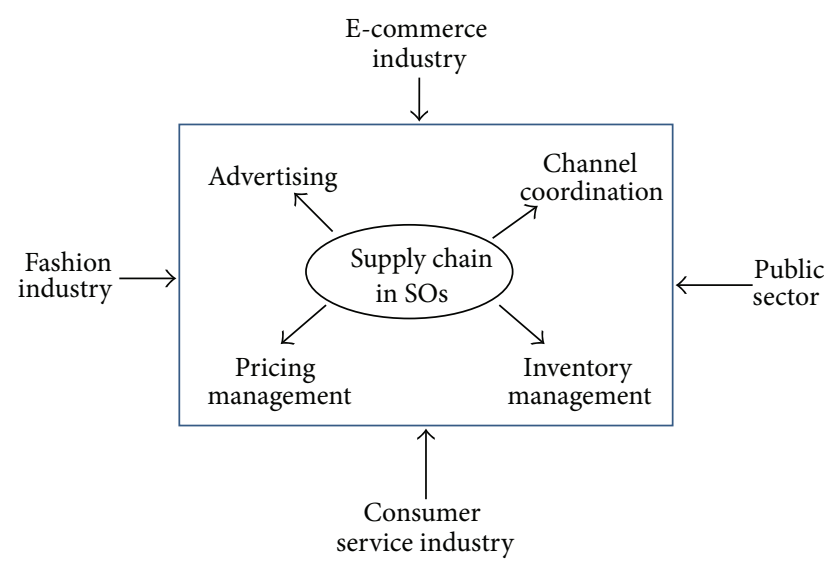

FIGURE 1: Recent development of supply chain in SOs.

optimally, and (3) identify what types of challenges exist in the SOs optimization. The literature on operation management has explored a wide range of SOs areas [6-8]. However, it is still new to discuss SOs optimization from the perspectives of supply chain management. Based on the theoretical optimization results, service managers should manage the tradeoff between operational costs and the provision of excellent service quality for attempting to maximize their payoff and the long-term market share. The analytical findings are able to be applied into the strategies of operation in practices and, as a result, help firms sustain the excellent service and gain business success. To the best of our knowledge, it is the first paper to discuss the recent development of SOs optimization from the perspectives of supply chain management.

This paper is organized as follows. We introduce SOs in Section 2. In Sections 3 and 4, we select four stylish topics in SOs management. Specifically, in Section 3, we review SOs with industries: e-commerce industry and consumer service industry; in Section 4, we review SOs with features: advertising and channel coordination. Section 5 concludes the paper with general implications and future research.

\section{SOs}

SOs are defined as the way to carry out the activities and processes which aim at achieving business success [2]. SOs are related to the whole process of business. Their characteristics are distinctive and are posing different challenges to SOs managers, who have to integrate and synchronize their joint activities in the whole business process related to supply chain management. In this section, we review the recent development of SOs. As shown in Figure 1, we classify the SOs into four different industries and four various features, respectively.

First, the adoption of SOs can be classified into the following four major industries, which are all stylish in the use of SOs.

2.1. E-Commerce Industry. Many IT firms provide the webbased retail platform service where the seller can trade the products or services with consumers. Examples of B2B platforms include Alibaba.com; B2C platforms include Amazon.com and Tmall.com; C2C platforms include eBay.com and Taobao.com. Millions of products are sold on the above web-based retail platforms. They enhance the service quality and manage the business process by the optimization approaches. Li and Lee [9] examine the service quality of webbased retail platform. They find that competition affects the platform owners' service quality. Jiang et al. [10] examine how the information of sellers' sales affects the strategic decisions made by a platform owner. They find that the platform owners may be worse off by retaining its option to sell the independent seller's product, but online sellers may be better off from the platform owner's threat of entry.

In addition, the platform of crowdsourcing is popular in e-commerce. Crowdsourcing helps designers make their innovative ideas feasible. Examples of crowdsourcing platforms include Teespring.com, Threadless.com, and Dell IdeaStorm Community. Based on the feature of fashion business in the crowdsourcing platform, Dai et al. [11] examine the online designer trading platform, in which designers can post their design samples or sketches of products and consumers can preorder the products. They find that (1) the minimum production quantity should be determined by the platform and (2) the retail business is still profitable if the retail price is determined as low as possible to enlarge the market demand. As it is quite popular to launch the webbased retail platform in e-commerce, we provide a technical review on how the platform owners provide good service to consumers in Section 3.1.

2.2. Consumer Service Industry. In consumer service industry, time is an important criterion for the quality of service [3]. Customers are increasingly depending on fast response, namely, less waiting service time. Service time thus is the key for business success. Boyaci and Ray [12] suggest that firms can differentiate their products based on service time. So [13] suggests that the competition could affect the equilibrium price and time guarantee decisions. Moreover, they find that when time attractiveness of the market increases, firms would compete less on market price. Xiao et al. [14] examine the lead time problem in a single retailer and a single manufacturer supply chain. They find that in the decentralized supply chain lead time is decreasing in the unit remanufacturing cost, the unit production cost, and unit returning loss. Due to the importance in operation management, in Section 4.1, we provide a technical review regarding service time in consumer service industry.

2.3. Public Sector. Evaluating the quality of service is essential to public sector such as library and hospital. In library, users look for the prompt response of information feedback. Ahmed and Shoeb [15] identify the four dimensions of service quality in university library website, which include effect of service (organizational), collection and access, library as a place, and effect of service (personal). In addition, service is an important part of healthcare system. For example, the service level of emergency department is the determinant for the quality of healthcare service. Green et al. [16] assess the effectiveness of queuing model in the emergency department 
staffing and identify the staffing patterns to reduce the fraction of patients who leave without being seen.

2.4. Fashion Industry. Services are important in the fashion industry $[17,18]$. Given the analytical tool for firms to make the best decisions, the intelligence decision support systems such as forecasting are critical in the fashion supply chain [19]. A good forecasting service system can help increase the customer service level by avoiding the mismatch between supply and demand and increasing supply chain efficiency. In addition, in order to gain the business core value, many fashion firms start to not only outsource manufacturing [20], but also design innovation service to their suppliers [21]. Shen et al. [21] examine how design outsourcing service affects the performance of supply chain parties in the fashion supply chain. They find that under the wholesale price contract the supplier has no incentive to enhance the design innovation service.

Services are critically strategic decisions that could increase a company's profitability and enlarge its operational cost according to the features of services. In addition to the adoption of SOs in various industries, SOs can be categorized into the following major four features from supply chain perspective.

(i) Advertising. Advertising is one kind of services in marketing and plays a determinant role of building up brand image. To reach a wider range of consumers, firms adopt advertising strategies to influence the consumer behavior and enlarge market demand. However, in the meanwhile, firms have to burden high operational cost in advertising. Bass et al. [22] suggest that the brand advertising is effective for the short-term market share and the generic advertising is more effective for the long-run market share. Zheng et al. [23] examine the impact of social influence in advertising service and find that the budget of advertising should be separated into both fashion leaders and fashion followers, instead of fashion leaders only or fashion followers only.

Moreover, one of popular research directions in advertising SOs is the cooperative advertising. Norman et al. [24] find that the advertising intensity would influence the market concentration. They find that when an advertising campaign is sufficiently costly, no advertising will occur regardless of the concentration level. Viscolani [25] suggests that in the homogenous market advertising could influence the product demand. Due to the importance in business, we provide a technical review regarding how the advertising is adopted in SOs in Section 3.2.

(ii) Channel Coordination. Channel coordination is one of the top management objectives in supply chain. The supply chain parties can receive the benefits from achieving supply chain coordination when they provide the services to the customers [26]. More importantly, the contemporary supply chain incorporates the modern approaches of SOs such as just-intime [27], vendor managed inventory [28], and RFID [29] to integrate the supply chain and increase the achievability of channel coordination. Desiraju and Moorthy [30] study information asymmetry between supplier and retailer and they find that adjusting the price or service can improve supply chain performance. They also find that coordination is able to achieve through requiring service performance. Boyaci and Gallego [31] examine the customer service competition in two competing supply chains. They find that the coordination is a dominant strategy and the first mover is able to take the advantages in providing better service. Channel coordination is an important topic in SOs; thus we technically review how coordination issues are managed by the optimization approach in SOs of supply chain in Section 4.2.

(iii) Pricing. Price plays an important role in SOs. Pricing information is one kind of services in the e-commerce environment and is affecting the decision making between retailers and suppliers regarding own prices. Bashyam [32] argues that information service providers commit the service design based on the feasible pricing strategies. Lahiri et al. [33] find that, in the wireless industry, the discriminatory pricing in SOs may harm social welfare and reduce profit.

(iv) Inventory. Service level is one of the determinant factors for the inventory holding cost and the service quality regarding inventory. Teunter et al. [34] propose an optimal control approach to minimize inventory costs whilst maximizing service level. They find three important factors to enhance the service level in inventory: (1) inventory policies, (2) frequency of stock counts, and (3) frequency of orders. Moreover, service inventory is different from physical product inventory. Service inventory can help firms to offer better quality, faster response times, and more competitive prices [35]. Service inventory is mainly based on information availability. The provision of information requires the cooperation and trust between service providers and users.

\section{SOs with Industries}

3.1. SOs in E-Commerce Industry. Selling products in webbased retail platforms has been the mainstream in ecommerce industry. In this subsection, we focus on reviewing the work of Choi et al. [4] which investigates the optimal SOs in web-based retail platform Taobao.com, the hottest online shopping platforms in China. Choi et al. [4] examine the customer service of online shopping platforms (OSP). First, they conduct a case-based empirical study regarding Taobao.com and find that the online customer loyalty $l$ is significantly related to the "fulfillment and responsiveness" function $\lambda$. Second, driven by the empirical result, they build up the analytical model in which the customer loyalty $l$ is increasing in the "fulfillment and responsiveness" function $\lambda$ as follows:

$$
l=a+b \lambda, \quad \text { where } a, b>0 .
$$

Afterwards, they consider that the revenue function of web-based retailer platform is stochastic. Specifically, a higher level of customer loyalty $l$ leads to a higher platform's revenue $R(l)$; namely, they have the following equation:

$$
R(l)=G(l)+\varepsilon,
$$

where (i) $G(l)$ is concave and is an increasing function of $l$ and (ii) $\varepsilon$ is a random variable and follows a symmetric 
distribution such as normal distribution with a zero mean and constant variance $\sigma^{2}$. Moreover, they consider that the cost function $C(\lambda)$ is convex function and an increasing in $\lambda$.

They denote the profit of OSP as $\pi(\lambda)$, the corresponding expected profit as $E[\pi(\lambda)]$, and the corresponding variance of profit as $V[\pi(\lambda)]$. The functions above are as follows:

$$
\begin{gathered}
\pi(\lambda)=R(l)-C(\lambda) \\
=G(a+b \lambda)-C(\lambda)+\varepsilon, \\
E[\pi(\lambda)]=G(a+b \lambda)-C(\lambda), \\
V[\pi(\lambda)]=\sigma^{2} .
\end{gathered}
$$

They consider that the OSP is risk averse. They examine the OSP's performance associated with risk by using the mean-variance safety first measure $(\operatorname{SFM}(\lambda))$ as the objective function for the OSP:

$$
\operatorname{SFM}(\lambda)=\frac{(E[\pi(\lambda)]-\beta)}{\sqrt{V[\pi(\lambda)]}},
$$

where $\beta$ is the expected profit target that the OSP expects to achieve. The mean-variance safety first measure is innovative in SOs, which could trace back to the prestigious meanvariance approach [36] and safety-first principle in portfolio selection model [37]. The mean-variance safety first measure is a risk management technique and could provide the optimal control strategy when considering payoff and risk.

Choi et al.s work [4] is a multimethodological study. They first investigate the service quality in OSP empirically, and then, based on the empirical results, they further examine the optimal service quality analytically. They find that $\lambda_{\mathrm{SFM}}^{*}$ and $\lambda_{\mathrm{EP}}^{*}$ uniquely exist and $\lambda_{\mathrm{SFM}}^{*}=\lambda_{\mathrm{EP}}^{*}$. Their results imply that the optimal level of "fulfillment and responsiveness" for risk averse OSP is equivalent to the one for risk neutral. In other words, the optimal service level does not depend on the risk preference of the OSP.

3.2. SOs in Consumer Service Industry. Service time is significantly important in consumer service industry. In this subsection, we focus on reviewing Park and Hong's work in [38]. Park and Hong [38] consider the case where the market demand is influenced by not only the retail price and service level, but also service time. They consider that the retailer sells a product to customers at retail price $p$, and the supplier sets the service level $s$ and the guaranteed service time $l$. The customer demand arrives according to a Poisson process with a mean rate $\lambda$. They consider that the demand function is

$$
\lambda(p, l, s)=a-b p-c l+g s
$$

where $a$ is the potential market size and $b, c$, and $g$ represent the degree of sensitivity of price, the service time, and the service level to the mean demand rate.

They also consider that the investment costs are $\mu A$, the unit variable cost is $m$, and the unit wholesale price is $w_{S}$.
The expected profit functions of retailer and supplier are as follows:

$$
\begin{gathered}
\pi_{R}(p)=\left(p-w_{S}\right) \lambda(p, l, s), \\
\pi_{S}(l, s, \mu)=\left(w_{S}-m\right) \lambda(p, l, s)-A \mu .
\end{gathered}
$$

The supplier's optimization problem is expressed as follows:

$$
\begin{array}{cl}
\max _{l, s, \mu}\left(w_{S}-m\right) \lambda(p, l, s)-A \mu, \\
\text { subject to } \quad & \lambda(p, l, s) \leq \mu, \\
& 1-e^{-(\mu-\lambda) l} \geq s, \\
& l>0, \quad \mu>0, \\
& 1>s \geq s_{C} .
\end{array}
$$

Constraint (8) implies system stability in that the supplier's mean service rate exceeds the mean demand rate. Constraint (9) is the actual service level which is larger than the proposed service. Constraint (10) represents the guaranteed service time and the capacity for the service/product is positive. Constraint (11) restricts the proposed service level which is greater than the industry standard service level $s_{C}$ and less than 1.

The retailer's optimization objective is expressed as follows:

$$
\max _{p}\left(p-w_{S}\right) \lambda(p, l, s) .
$$

The profit function of retailer $\pi_{R}(p)$ is the concave function of $p$. Thus, the optimal retail price, $p^{*}$, is able to be obtained by taking the first-order derivative of the retailer's profit function. The profit function of supplier is jointly concave with respect to $s$ and $l$; thus the optimal service level $s^{*}$ and the optimal guaranteed service time $l^{*}$ can be derived.

Park and Hong [38] find that it is more desirable to simultaneously determine the optimal price, the optimal guaranteed service time, and the optimal service level, instead of sequentially in consumer service industry. This finding implies that the central planner can help maximize the supply chain profit. The service supply chain with service time and service level is better to determine the service time and service level simultaneously by the central planner.

\section{SOs of Supply Chain}

4.1. SOs of Advertising. One stream of the literature has investigated the advertising investment issue in SOs management. In this subsection, we focus on reviewing Xu et al. [39]. Xu et al. [39] investigate the advertising competition in three advertising game models: Cooperative game, Boxed Pig game, and Prisoner's game. These three models comprehensively represent the SOs of advertising. They consider two different sizes of service providers in one service market. One is the dominant service provider $(D)$ who occupies major market share $w_{D}$. The other is $M$ small service providers (S) who share the remaining market share $1-w_{D}$ equally, where $w_{D} \gg w_{i}$ and $w_{D}+\sum_{i=1}^{M} w_{i}=1$. 
They consider that the service provider $D$ (or $S$ ) can decide whether or not to invest in advertising. They summarize four cases.

Case 1. Both service providers $D$ and $S$ choose to invest in advertising. They denote the total investment on advertising as $I$. The service provider $D$ has $a I$ and the service provider $S$ has $b I$, where $a+b=1$. They also denote $l(l>1)$ as the resource coefficient, where $a I=l b I$, and $k(k>1)$ as the effect of cooperative advertising, where $R_{D 1}=k b l I$ and $R_{S 1}=k b I$. The payoff functions are as follows:

$$
\begin{gathered}
\pi_{D 1}=(1-\theta) k b l I-b l I+\lambda k b l I, \\
\pi_{S 1}=(1-\theta) k b I-b I+\lambda k b I .
\end{gathered}
$$

Case 2. Service provider $D$ advertises, but service provider $S$ waits. The effect of advertising coefficient is $k_{D}$ and the service provider D's advertising investment is $R_{D 2}=b l k_{D} I$. The payoff functions are as follows:

$$
\begin{gathered}
\pi_{D 2}=(1-\theta) k_{D} b l I-b l I+\lambda k_{D} b l I, \\
\pi_{S 2}=\frac{\theta}{M} k_{D} b l I .
\end{gathered}
$$

Case 3. Service provider $S$ advertises, but service provider $D$ waits. Similarly, the effects of advertising coefficient are $k_{S}$, where $k>k_{D}>k_{S}$. The payoff functions are as follows:

$$
\begin{gathered}
\pi_{D 3}=\frac{\theta}{M} \beta k_{S} b l I, \\
\pi_{S 3}=(1-\theta) k_{S} b I-b I+\lambda k_{D} b I,
\end{gathered}
$$

where $\beta(\beta>1)$ is the spillover effect of service provider $D$.

Case 4. Noncooperative advertising, namely, no service provider, chooses to offer advertising. The payoff functions are $\pi_{D 4}=\pi_{S 4}=0$.

$\mathrm{Xu}$ et al. [39] derive the various conditions and identify the optimal decisions for different advertising games. They find that the advertising spillover and the number of the small service providers $S$ would significantly influence the optimal strategies in advertising mode selection. Comparing the results of the above four cases, they find that the service providers can achieve the advertising synergy effects through Case 1. Therefore, they conclude that service providers should collaborate with each other in order to optimize their payoff and gain the most revenue instead of taking free ride.

4.2. Channel Coordination in Service Supply Chain. Channel coordination is the key competitive dimension in supply chain $[40,41]$. In this subsection, we focus on reviewing the work of He et al. [42]. He et al. [42] study the coordination issues in a two-period supply chain in which there are a single manufacturer and a single retailer. They consider two cases: (1) manufacturer and retailer make decisions within a cooperative advertising program and (2) the retailer is vertically integrated with a manufacturer. They denote the manufacturer's quality effort as $x$. Moreover, they denote the retailer's advertising efforts as $e_{1}$ and $e_{2}$ and the market demand as $D_{1}$ and $D_{2}$. They consider that the market demand in the first period is a linear function of manufacturer's quality effort $x$ and first-period retailer's advertising efforts $e_{1}$ as follows:

$$
D_{1}=\alpha_{1}+\beta x+\lambda e_{1}
$$

where $\beta$ and $\lambda$ are both positive and $\alpha_{1}\left(\alpha_{1} \gg 0\right)$ is the potential intrinsic demand. In the second period, the market demand is increasing in second-period retailer's advertising efforts $e_{2}$ as follows:

$$
D_{2}=\alpha_{2}+\theta \lambda e_{2}
$$

where $\theta$ is constant and $\alpha_{2}\left(\alpha_{2} \gg 0\right)$ is the potential intrinsic demand in the second period. They consider that the cost functions of quality $(C(x))$ and advertising $\left(C\left(e_{i}\right)\right)$ are quadratic with respect to quality effort $x$ and advertising effort $e_{i}$, respectively:

$$
\begin{gathered}
C(x)=x^{2}, \\
C\left(e_{i}\right)=\frac{1}{2} e_{i}^{2}, \quad i \in\{1,2\} .
\end{gathered}
$$

They consider that the manufacturer's profit margin for each unit in the period $i$ is $\rho_{m i}$ and the retailer's profit marginal in the period $i$ is $\rho_{r i}$. The profit functions of manufacturer and retailer are expressed as follows:

$$
\begin{gathered}
\pi_{m}=\rho_{m 1} D_{1}+\rho_{m 2} D_{2}-x^{2}, \\
\pi_{r}=\rho_{r 1} D_{1}+\rho_{r 2} D_{2}-\frac{1}{2} e_{1}^{2}-\frac{1}{2} e_{2}^{2} .
\end{gathered}
$$

They first examine the situation where the manufacturer provides two different subsidy rates $\left(\phi_{1}\right.$ and $\left.\phi_{2}\right)$ to the retailer during the two periods. The profit functions of manufacturer and retailer are expressed as follows:

$$
\begin{gathered}
\pi_{m}=\rho_{m 1} D_{1}+\rho_{m 2} D_{2}-x^{2}-\phi_{1} \frac{1}{2} e_{1}^{2}-\frac{1}{2} \phi_{2} e_{2}^{2}, \\
\pi_{r}=\rho_{r 1} D_{1}+\rho_{r 2} D_{2}-\frac{1}{2}\left(1-\phi_{1}\right) e_{1}^{2}-\frac{1}{2}\left(1-\phi_{2}\right) e_{2}^{2} .
\end{gathered}
$$

Second, they study the situation where the manufacturer provides the same subsidy rate $(\phi)$ to the retailer during the two periods. The profit functions of manufacturer and retailer are expressed as follows:

$$
\begin{gathered}
\pi_{m}=\rho_{m 1} D_{1}+\rho_{m 2} D_{2}-x^{2}-\phi \frac{1}{2} e_{1}^{2}-\frac{1}{2} \phi e_{2}^{2}, \\
\pi_{r}=\rho_{r 1} D_{1}+\rho_{r 2} D_{2}-\frac{1}{2}(1-\phi) e_{1}^{2}-\frac{1}{2}(1-\phi) e_{2}^{2} .
\end{gathered}
$$

He et al. [42] examine the impacts of different subsidy policies on supply chain. They find that both the manufacturer's optimal quality effort and the retailer's first-period 
advertising effort are influenced by the centralized firstperiod profit margin. Therefore, the quality effort and advertising effort are the determinant factors for the centralized supply chain profit in the first period. Furthermore, He et al. [42] find the optimal advertising efforts for the retailer during the two periods. They also derive the optimal quality effort and subsidy policies for the manufacturer during the two periods. Moreover, they find that the two-way subsidy contract can coordinate both the one-period and two-period advertising models. This study implies that the integration between supply chain and advertising program is beneficial to supply chain coordination.

\section{Conclusions}

It is preferred to design and implement SOs in the optimized ways. In this paper, we investigate the recent development of SOs optimization from supply chain perspective. We review four different industries (i.e., e-commerce industry, consumer service industry, public sector, and fashion industry) and four various SOs features (i.e., advertising, channel coordination, pricing, and inventory) related to SOs optimization, respectively. The most aspects of SOs optimization in literature of supply chain are included and all selected topics are highly representative in SOs management. Moreover, we select four important topics to conduct the technical review and study how business success is affected by SOs towards optimization. To be specific, we review the topics of e-commerce industry and consumer service industry and advertising and coordination in supply chain. We find that it is significant to integrate all supply chain parties or features in SOs. This integration helps the firms to find the linkage of success within the whole business process. The decisions derived by optimal control approach are feasible in helping the continual improvement activities in SOs management. We suggest that the service manager should provide a constant level of customer service for long-term market share.

Based on the extant literature, three challenges that exist in the SOs by optimal control approach are as follows.

(i) Managing Service Capacity. Services are different from the physical products. Strategies for managing demand and supply in SOs are critical [43]. Netessine et al. [43] develop a relatively simple approach to determine the optimal service capacity in consideration of service delivery. It would be interesting to explore what the optimal strategies for service capacity are and how SOs achieve tradeoff between the service capacity level and service quality.

(ii) Service Technology. The quality of service is strongly influenced by technology. To overcome this inherent problem, investment in service technology turns out to be significantly important [44]. It has rare research using optimal control approach to study how service technology affects performance in operation management. It would be interesting to investigate the optimal strategy between investment in technology and cost reduction in SOs.

(iii) Linkage between Operational Performance and SOs. The importance of performance in SOs such as service quality, service design, and service sustainability has received growing awareness [45]. However, it has rare research using optimal control approach to study the linkage between SOs and operational performance. It would be interesting to find out the linkage between operational performance and business success.

\section{Conflict of Interests}

The author declares that there is no conflict of interests regarding the publication of this paper.

\section{Acknowledgments}

The author would like to thank an editor and two anonymous referees for their constructive comments and suggestions on earlier versions of this paper. The author is supported by the Shanghai Pujiang Program (14PJ1400200) and the National Natural Science Foundation of China (71401029).

\section{References}

[1] P. Lillrank and M. Särkkä, "The service machine as a service operation framework," Strategic Outsourcing, vol. 4, no. 3, pp. 274-293, 2011.

[2] R. Johnston, "Service operations management: return to roots," International Journal of Operations and Production Management, vol. 19, no. 2, pp. 104-124, 1999.

[3] M. M. Davis and T. E. Vollmann, "A framework for relating waiting time and customer satisfaction in a service operation," Journal of Services Marketing, vol. 4, no. 1, pp. 61-69, 1990.

[4] T.-M. Choi, P.-S. Chow, B. Kwok, S.-C. Liu, and B. Shen, "Service quality of online shopping platforms: a case-based empirical and analytical study," Mathematical Problems in Engineering, vol. 2013, Article ID 128678, 9 pages, 2013.

[5] E. Todorov, "Optimal control theory", in Bayesian Brain, MIT Press, Cambridge, Mass, USA, 2006.

[6] J. Gu, M. Goetschalckx, and L. F. McGinnis, "Research on warehouse design and performance evaluation: a comprehensive review," European Journal of Operational Research, vol. 203, no. 3, pp. 539-549, 2010.

[7] P. P. Datta and R. Roy, "Cost modelling techniques for availability type service support contracts: a literature review and empirical study," CIRP Journal of Manufacturing Science and Technology, vol. 3, no. 2, pp. 142-157, 2010.

[8] M. S. Hossain and A. El-shafie, "Intelligent systems in optimizing reservoir operationpolicy: a review," Water Resources Management, vol. 27, no. 9, pp. 3387-3407, 2013.

[9] Y.-M. Li and Y.-L. Lee, "Pricing peer-produced services: quality, capacity, and competition issues," European Journal of Operational Research, vol. 207, no. 3, pp. 1658-1668, 2010.

[10] B. Jiang, K. Jerath, and K. Srinivasan, "Firm strategies in the 'mid tail' of platform-based retailing," Marketing Science, vol. 30, no. 5, pp. 757-775, 2011.

[11] X. Dai, P.-S. Chow, J.-H. Zheng, and C.-H. Chiu, "Crowdsourcing new product design on the web: an analysis of online designer platform service," Mathematical Problems in Engineering, vol. 2013, Article ID 248170, 13 pages, 2013.

[12] T. Boyaci and S. Ray, "Product differentiation and capacity cost interaction in time and price sensitive markets," Manufacturing 
and Service Operations Management, vol. 5, no. 1, pp. 18-36, 2003.

[13] K. C. So, "Price and time competition for service delivery," Manufacturing and Service Operations Management, vol. 2, no. 4, pp. 392-409, 2000.

[14] T. Xiao, D. Yang, and H. Shen, "Coordinating a supply chain with a quality assurance policy via a revenue-sharing contract," International Journal of Production Research, vol. 49, no. 1, pp. 99-120, 2011.

[15] S. M. Z. Ahmed and M. Z. H. Shoeb, "Measuring service quality of a public university library in Bangladesh using SERVQUAL," Performance Measurement and Metrics, vol. 10, no. 1, pp. 17-32, 2009.

[16] L. V. Green, J. Soares, J. F. Giglio, and R. A. Green, "Using queueing theory to increase the effectiveness of emergency department provider staffing," Academic Emergency Medicine, vol. 13, no. 1, pp. 61-68, 2006.

[17] B. Shen, "Sustainable fashion supply chain: lessons from H\&M," Sustainability, vol. 6, no. 9, pp. 6236-6249, 2014.

[18] B. Shen, J.-H. Zheng, P.-S. Chow, and K.-Y. Chow, "Perception of fashion sustainability in online community," Journal of the Textile Institute, vol. 105, no. 9, pp. 971-979, 2014.

[19] T. M. Choi, C. L. Hui, N. Liu, S. F. Ng, and Y. Yu, "Fast fashion sales forecasting with limited data and time," Decision Support Systems, vol. 59, no. 1, pp. 84-92, 2014.

[20] B. Shen, T.-M. Choi, Y. L. Wang, and C. K. Y. Lo, “The coordination of fashion supply chains with a risk-averse supplier under the markdown money policy," IEEE Transactions on Systems, Man, and Cybernetics, Part A: Systems and Humans, vol. 43, no. 2, pp. 266-276, 2013.

[21] B. Shen, Q. Y. Li, and C. W. Dong, "Design outsourcing in fashion supply chain: OEM v.s. ODM," Working Paper, 2014.

[22] F. M. Bass, A. Krishnamoorthy, A. Prasad, and S. P. Sethi, "Generic and brand advertising strategies in a dynamic duopoly," Marketing Science, vol. 24, no. 4, pp. 556-568, 2005.

[23] J. H. Zheng, C. H. Chiu, and T. M. Choi, "Optimal advertising and pricing strategies for luxury fashion brands with social influences," IEEE Transactions on Systems, Man, and Cybernetics Part A: Systems and Humans, vol. 42, no. 4, pp. 827-837, 2012.

[24] G. Norman, L. Pepall, and D. Richards, "Generic product advertising, spillovers, and market concentration," The American Journal of Agricultural Economics, vol. 90, no. 3, pp. 719-732, 2008.

[25] B. Viscolani, "Pure-strategy Nash equilibria in an advertising game with interference," European Journal of Operational Research, vol. 216, no. 3, pp. 605-612, 2012.

[26] B. Shen, P.-S. Chow, and T.-M. Choi, "Supply chain contracts in fashion department stores: coordination and risk analysis," Mathematical Problems in Engineering, vol. 2014, Article ID 954235, 10 pages, 2014.

[27] R. Z. Farahani and M. Elahipanah, "A genetic algorithm to optimize the total cost and service level for just-in-time distribution in a supply chain," International Journal of Production Economics, vol. 111, no. 2, pp. 229-243, 2008.

[28] T.-M. Choi, "Coordination and risk analysis of VMI supply chains with RFID technology," IEEE Transactions on Industrial Informatics, vol. 7, no. 3, pp. 497-504, 2011.

[29] H. L. Chan, T. M. Choi, and C. L. Hui, "RFID versus bar-coding systems: transactions errors in health care apparel inventory control," Decision Support Systems, vol. 54, no. 1, pp. 803-811, 2012.
[30] R. Desiraju and S. Moorthy, "Managing a distribution channel under asymmetric information with performance requirements," Management Science, vol. 43, no. 12, pp. 1628-1644, 1997.

[31] T. Boyaci and G. Gallego, "Supply chain coordination in a market with customer service competition," Production and Operations Management, vol. 13, no. 1, pp. 3-22, 2004.

[32] T. C. A. Bashyam, "Service design and price competition in business information services," Operations Research, vol. 48, no. 3, pp. 362-375, 2000.

[33] A. Lahiri, R. M. Dewan, and M. Freimer, "Pricing of wireless services: service pricing vs. traffic pricing," Information Systems Research, vol. 24, no. 2, pp. 418-435, 2013.

[34] R. H. Teunter, M. Z. Babai, and A. A. Syntetos, "ABC classification: service levels and inventory costs," Production and Operations Management, vol. 19, no. 3, pp. 343-352, 2010.

[35] S. Chopra and M. A. Lariviere, "Managing service inventory to improve performance," MIT Sloan Management Review, vol. 47, no. 1, pp. 56-95, 2005.

[36] H. M. Markowitz, "Portfolio selection," The Journal of Finance, vol. 7, no. 1, pp. 77-91, 1952.

[37] A. D. Roy, "Safety first and the holding of assets," Econometrica, vol. 20, no. 3, pp. 431-449, 1952.

[38] S. Park and K. S. Hong, "Optimal guaranteed service time and service level decision with time and service level sensitive demand," Mathematical Problems in Engineering, vol. 2014, Article ID 694712, 7 pages, 2014.

[39] L. Xu, Z. Wang, J. Shan, and Y. Wang, "On advertising games and spillover in service systems," Mathematical Problems in Engineering, vol. 2013, Article ID 260823, 8 pages, 2013.

[40] C. W. Dong, B. Shen, P. S. Chow, L. Yang, and C. T. Ng, "Sustainability investment under cap-and-trade regulation," Annals of Operations Research, 2014.

[41] P.-S. Chow, Y. L. Wang, T.-M. Choi, and B. Shen, "An experimental study on the effects of minimum profit share on supply chains with markdown contract: risk and profit analysis," Omega, 2014.

[42] Y. He, Z. Liu, and K. Usman, "Coordination of cooperative advertising in a two-period fashion and textiles supply chain," Mathematical Problems in Engineering, vol. 2014, Article ID 356726, 10 pages, 2014.

[43] S. Netessine, G. Dobson, and R. A. Shumsky, "Flexible service capacity: optimal investment and the impact of demand correlation," Operations Research, vol. 50, no. 2, pp. 375-388, 2002.

[44] J.-S. C. Lin and P.-L. Hsieh, "Assessing the self-service technology encounters: development and validation of SSTQUAL scale," Journal of Retailing, vol. 87, no. 2, pp. 194-206, 2011.

[45] C.-L. Liu and A. C. Lyons, "An analysis of third-party logistics performance and service provision," Transportation Research Part E: Logistics and Transportation Review, vol. 47, no. 4, pp. 547-570, 2011. 


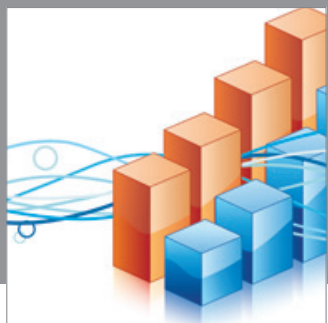

Advances in

Operations Research

mansans

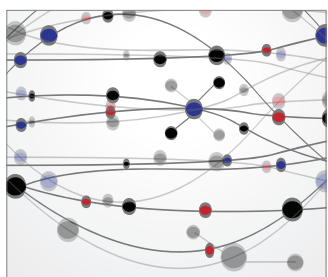

The Scientific World Journal
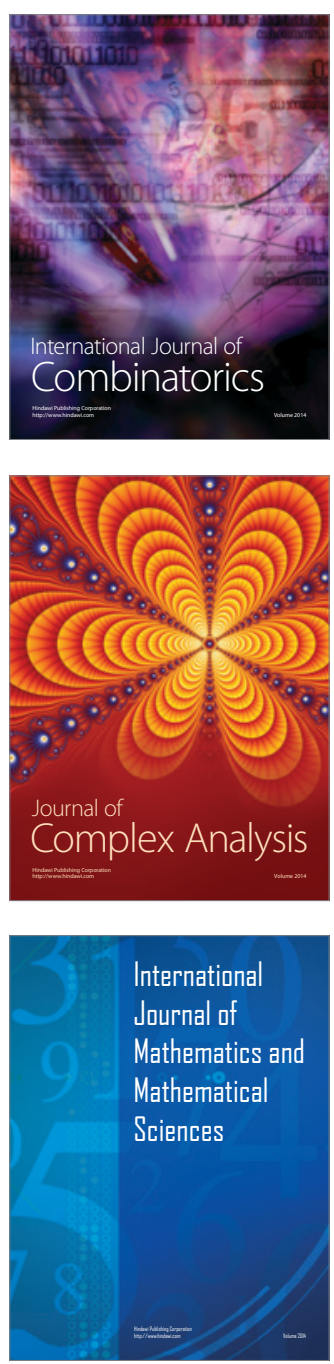
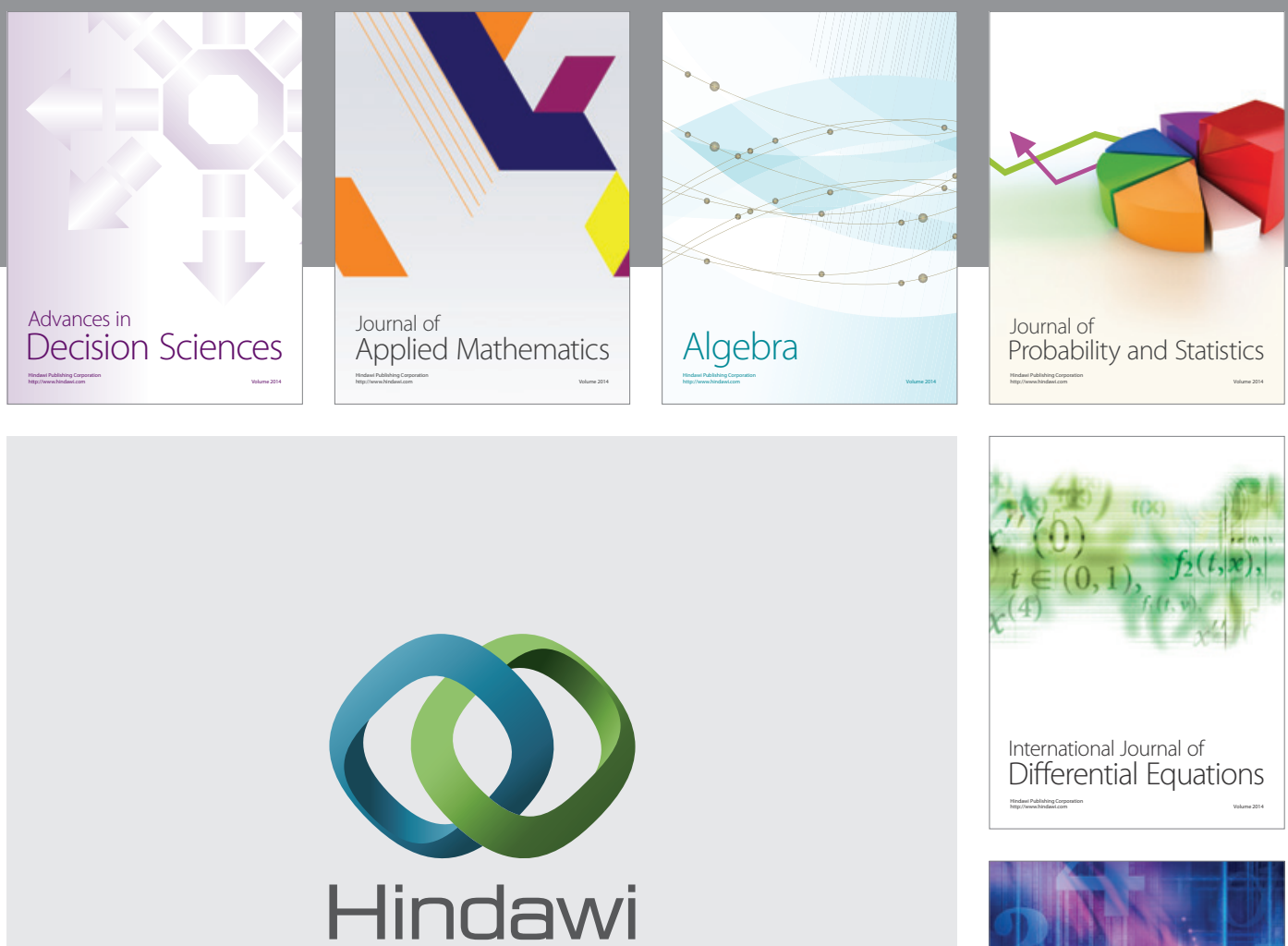

Submit your manuscripts at http://www.hindawi.com
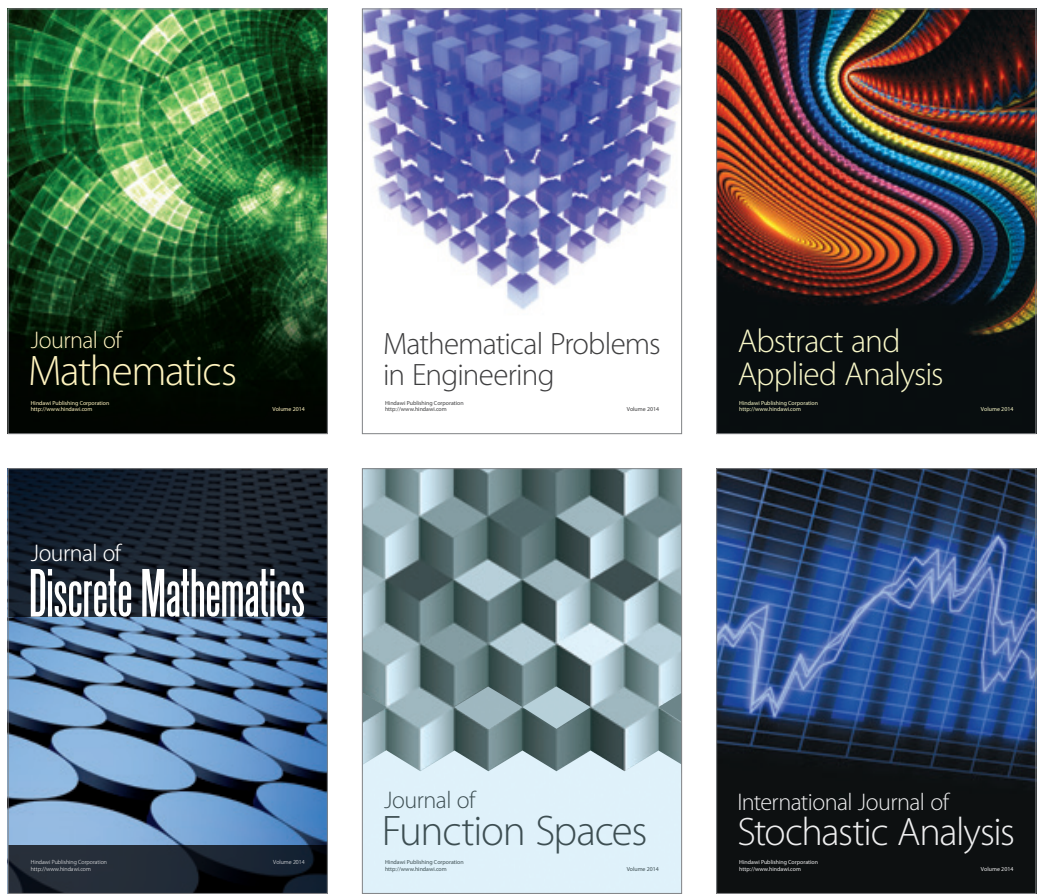

Journal of

Function Spaces

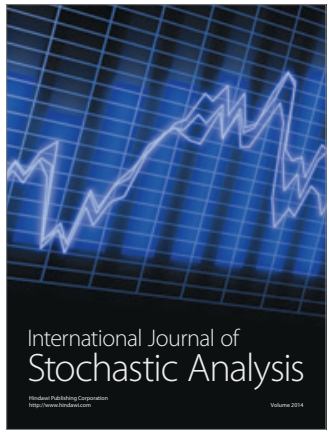

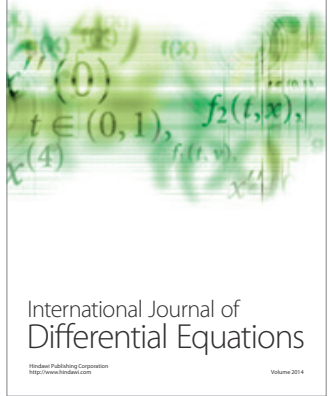
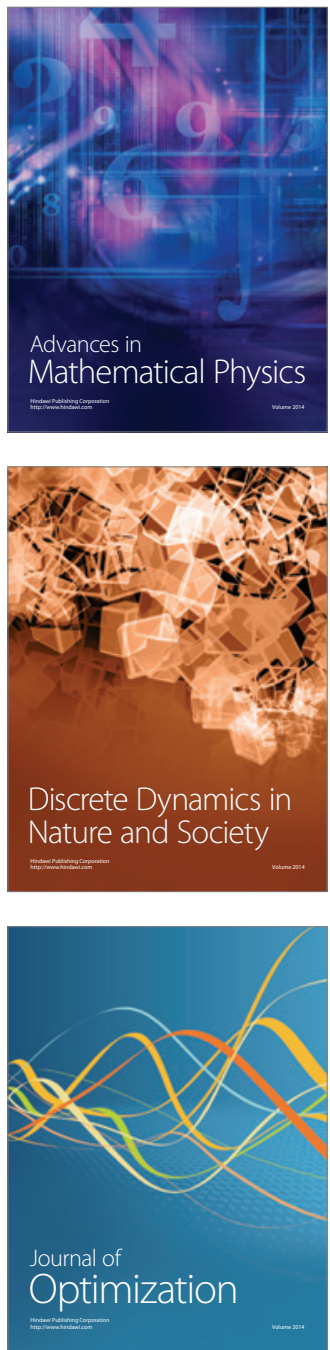